\title{
Structure-Function Relationships of the Vertebral Endplate
}

\author{
Yuanqiao $\mathrm{Wu}^{1}$, Johnfredy Loaiza ${ }^{1}$, Rohin Banerji ${ }^{2}$, Olivia Blouin ${ }^{2}$, Elise F. Morgan ${ }^{1,2}$
}

1. Department of Mechanical Engineering, Boston University, 110 Cummington Mall, Boston, MA 02215

2. Department of Biomedical Engineering, Boston University, 44 Cummington Mall, Boston, MA 02215

\begin{abstract}
Background: Although deformation and fracture of the vertebral endplate have been implicated in spinal conditions such as vertebral fracture and disc degeneration, few biomechanical studies of this structure are available. The goal of this study was to quantify the mechanical behavior of the vertebral endplate.

Methods: Eight-five rectangular specimens were dissected from the superior and/or inferior central endplates of human lumbar spine segments L1-L4. Micro-computed tomography ( $\mu$ CT) imaging, four-point-bend testing, and ashing were performed to quantify the apparent elastic modulus and yield stress (modulus and yield stress, respectively, of the porous vertebral endplate), tissue yield stress (yield stress of the tissue of the vertebral endplate, excluding pores), ultimate strain, fracture strain, bone volume fraction (BV/TV), bone mineral density (BMD), and various measures of tissue density and composition (tissue mineral density, ash fraction, and ash density). Regression was used to assess the dependence of mechanical properties on density and composition.
\end{abstract}

Results: Wide variations in elastic and failure properties, and in density and tissue composition, were observed. BMD and BV/TV were good predictors of many of the apparent-level mechanical properties, including modulus, yield stress, and in the case of the inferior vertebral endplate, failure strains. Similar values of the mechanical properties were noted between superior and inferior vertebral endplates. In contrast to the dependence of apparent stiffness and strength 
on BMD and BV/TV, none of the mechanical properties depended on any of the tissue-level density measurements.

Conclusion: The dependence of many of the mechanical properties of the vertebral endplate on $\mathrm{BV} / \mathrm{TV}$ and BMD suggests possibilities for non-invasive assessment of how this region of the spine behaves during habitual and injurious loading. Further study of the non-mineral components of the endplate tissue is required to understand how the composition of this tissue may influence the overall mechanical behavior of the vertebral endplate.

Keywords: Vertebral Endplate, Micro-Computed Tomography, Bending, Density, Fracture 


\section{INTRODUCTION}

The vertebral endplate, a thin, porous structure at the interface between the intervertebral disc and the trabecular centrum of the vertebral body, has been implicated in the etiology of two common causes of back pain, disc degeneration and vertebral fracture ${ }^{1,2}$. The vertebral endplate mediates fluid transport and load transfer between the disc and centrum of vertebral body, thereby serving an important structural and biochemical role in the spine ${ }^{3}$. Vertebral fractures, which affect at least $12-20 \%$ of men and women over the age of $50^{4-6}$, frequently occur at or near the vertebral endplate $^{7-9}$. Moreover, breakage of the vertebral endplate during vertebral fracture may lead to worsening of the fracture over time ${ }^{10}$ and degeneration of the adjacent intervertebral disc ${ }^{11-13}$. Thus, study of the mechanical behavior of the vertebral endplate and the dependence of this behavior on structure and composition can aid in understanding the development and consequences of vertebral fracture.

A limited amount of data is available on the mechanical properties of the tissue in the vertebral endplate ("tissue-level properties"14), and less is known about the mechanical behavior of the vertebral endplate as a structure ("apparent-level properties"). Previous studies have carried out micro-indentation tests on tissue from the vertebral endplate, vertebral trabecular bone, and the cortical shell, and have found similar elastic moduli among these three types of tissue ${ }^{15,16}$. However, given that the vertebral endplate has a preponderance of microscale pores, mechanical characterization at larger length scales is still needed. Several studies have used much larger indenters $(3 \mathrm{~mm}$ and $1.5 \mathrm{~mm})$ to indent across the superior and/or inferior endplate surface of the vertebra. These studies have generally found that the ring apophysis is stronger and stiffer than the central region ${ }^{17-21}$, although the opposite was found when the cartilage endplate was left attached to the vertebral endplate ${ }^{22}$. It is important to note that these macro-level indentation tests do not 
measure the properties of the vertebral endplate alone but rather those of the vertebral endplate together with some fraction of the rest of the vertebra. The indentation strength and stiffness measured in these types of macroscale tests are lower upon removal of the vertebral endplate ${ }^{23}$, which adds to the evidence of the mechanical importance of the vertebral endplate but does not provide direct quantification of its properties.

Despite the paucity of mechanical data on the vertebral endplate, data on its microstructure and composition suggest that its mechanical behavior may vary greatly. Porosity and thickness tend to be higher and lower, respectively, in the superior (relative to the vertebra) vertebral endplate compared to the inferior one ${ }^{24,25}$, which is consistent with clinical observations of a higher incidence of fractures in the superior half of the vertebral body ${ }^{26}$. Among individuals, variations in the bone mineral density (BMD) of the vertebral endplate are nearly as large as those in the BMD of the entire vertebral body and in the BMD of vertebral trabecular bone ${ }^{27}$. Some of this variation could be due to changes in porosity; for example, both Rodriguez et al. and Zehra et al. found that vertebral endplate porosity increases approximately two-fold over the course of disc degeneration ${ }^{28,29}$. However, conflicting reports exist as to whether porosity and BMD change with age $^{30}$, and the implications of the inter-and intra-individual variations in microstructure and composition for mechanical behavior are not yet known.

As such, the overall goal of this project was to characterize the mechanical behavior of the vertebral endplate. Rectangular specimens of the vertebral endplate were subjected to four-point bend tests and underwent microstructural and compositional analyses. Our specific objectives were: (1) to quantify the elastic, yield and fracture properties of superior and inferior vertebral endplates; and (2) to determine the dependence of these properties on measures of structure and composition. 


\section{MATERIALS AND METHODS}

\subsection{Specimen preparation}

L1-L4 vertebrae were obtained from 39 fresh frozen cadavers (24 males, 15 females) of mean age 77.7 years $($ stdev $=6.5$ years, range: $25-91$ years $)($ Figure 1$)$. The vertebral bodies were separated into superior and inferior halves with an autopsy saw, and on each half the cartilage endplate was removed with a scalpel to expose the vertebral endplate. The halves of the vertebral bodies were further trimmed using a diamond wafering blade (IsoMet 4000; Buehler, Lake Bluff, Illinois, USA) to produce a rectangular test specimen of the vertebral endplate with approximate dimensions $30 \mathrm{~mm} \times 13 \mathrm{~mm} \times 1.5 \mathrm{~mm}$ (Figure $2 \mathrm{~A}$ ). Due to the irregular thickness and surface topography of the vertebral endplate, the test specimens contained some struts of subchondral trabecular bone (Figure 2B). Five of the vertebral endplates produced two test specimens each, while the remaining 80 produced only one test specimen each.

\subsection{Micro-Computed Tomography $(\mu \mathrm{CT})$ scanning}

Each test specimen was submerged in PBS solution and imaged in a $\mu \mathrm{CT}$ scanner $(\mu \mathrm{CT} 40$; Scanco Medical, Brüttisellen, Switzerland, $16 \mu \mathrm{m} /$ voxel, $70 \mathrm{kV}, 114 \mu \mathrm{A})$. A threshold of $510 \mathrm{mg} \mathrm{HA} / \mathrm{cm}^{3}$ (215 per-mille), determined from an adaptive, iterative technique (Scanco Medical), was used to binarize those $\mu \mathrm{CT}$ images. Bone volume fraction (BV/TV), bone mineral density (BMD), and tissue mineral density (TMD) were quantified for the central $16 \mathrm{~mm}$ of the specimens; this region corresponds to the flexural span in the bend tests. BMD was defined as the average density of all voxels in the 16mm span and is akin to apparent density, whereas TMD was defined as the average density of only the voxels within the $16 \mathrm{~mm}$ span whose mineral density was above the threshold. Plate thickness (Figure 2B) was measured using the 3-D thickness measurement algorithm in BoneJ $^{31}$, which computes local values of thickness throughout the structure and then averages 
these. Although some of the local thicknesses corresponded to the trabecular struts, their effect on the resulting average was small due to the small percentage of struts present.

\subsection{Mechanical testing}

Following $\mu \mathrm{CT}$ scanning, each specimen was placed on the support pins of a four-point-bend test fixture (inner $\operatorname{span}=8 \mathrm{~mm}$, outer $\operatorname{span}=16 \mathrm{~mm})$ in an electromechanical test frame $($ model 5565 ; Instron, Norwood, Massachusetts, USA) (Figure 2C). Specimens were oriented such that the surface of the vertebral endplate was placed in compression during the bend test, to mimic the type of concavity that develops in most clinical vertebral fractures in the elderly. After 15 cycles of preconditioning to $0.75 \mathrm{~mm}$, each specimen was loaded to failure at a rate of $0.21 \mathrm{~mm} / \mathrm{sec}$. Force and displacement were measured with a $1 \mathrm{kN}$ load cell and the test frame's LVDT, respectively; the measured displacement was that of the outer pins. The test was stopped when either failure of specimen occurred (defined as the force dropping to zero) or when the displacement limit of the test was reached (defined as the onset of pinching of the specimen between the upper pins and the sides of the bottom fixture, Figure 3A).

The apparent modulus and apparent yield stress were computed using linear elastic beam theory:

$$
\begin{gathered}
E=\frac{L^{2} \times k}{12 \times I} \\
\sigma_{y}=\frac{M_{y} \times h}{2 \times I}
\end{gathered}
$$

where $\mathrm{k}$ is the maximum slope of the moment-displacement curve prior to any local maximum in the curve (red line in Figure 2D), $M_{y}$ is the moment just after this region of maximum slope (red triangle in Figure), $\mathrm{L}=16 \mathrm{~mm}, I=1 /\left(12 \times b \times h^{3}\right)$, and $b$ and $h$ are the width and thickness of 
the central $16 \mathrm{~mm}$ of the specimen. The tissue-level yield stress $\left(\sigma_{\text {tissue }}\right)$ was calculated at the apparent yield point, using $M_{y} / S_{\min }$, where $S_{\min }$ is the minimum section modulus and was computed according to published methods ${ }^{32,33}$ by considering all bone voxels (voxels above the threshold) within the $16 \mathrm{~mm}$ span in the $\mu \mathrm{CT}$ image.

Video taken of the mechanical tests was synchronized to the loading curve and used to compute ultimate and fracture strains. In the still frame corresponding to the ultimate point, the curvatures of upper and lower boundaries of the $16 \mathrm{~mm}$ span of the specimen were determined using edge detection and best-fit circles (MATLAB) and then averaged. Ultimate strain $\left(\varepsilon_{\mathrm{u}}\right)$ was calculated as the distance between two edges divided by the average of the two circles' radii. For 25 specimens, the fracture strain $\left(\varepsilon_{\mathrm{f}}\right)$ was calculated using the same method for calculating the $\varepsilon_{\mathrm{u}}$, except at the point in the test when an audible cracking noise occurred at the same time as a sudden drop bending moment. For some specimens, the fracture point coincided with the ultimate point, whereas for others, it occurred after the ultimate point. Due to the displacement limit of the test, the ultimate strain and fracture strain were not obtainable for all the specimens.

\subsection{Measurements of tissue and ash densities}

After mechanical testing, each specimen was gently cleaned with a water jet to remove the bone marrow and then weighed (Mettler AT 200; Mettler Toledo, Columbus, Ohio, USA) in air and again in degassed water in order to calculate the tissue density ( $\left.\rho_{\text {tissue }}\right)$ using Archimedes' principle. Specimens were then defatted in acetone for 12 hours and cut in half, and one half was retained for measurement of ash density. The tissue volume of this half was also calculated using Archimedes' principle and was then dried in a muffle furnace (Thermolyne Furnace 47900, Thermo Fisher Scientific, Waltham, MA, USA) at $110^{\circ} \mathrm{C}$ for two hours to obtain the dry weight. The dried specimen was then put back to the furnace for another 14 hours under $650^{\circ} \mathrm{C}$ to obtain 
the ash weight. Ash fraction $(p)$ and ash density $\left(\rho_{\text {ash }}\right)$ were computed as the ratio of ash weight to dry weight and ash weight to tissue volume, respectively. Finally, the ash weight, water weight and organic weight were each computed as a percentage of the tissue weight.

\subsection{Statistical analyses}

In cases where two specimens were obtained from the same half vertebral body, the mean value over the two specimens was used in the statistical analyses. All properties except TMD, $p$, $\varepsilon_{\mathrm{u}}$ and $\varepsilon_{\mathrm{f}}$ were log-transformed to follow the normal distribution assumption of statistical models. Linear regression (JMP, SAS Institute) analysis was used to determine the dependence of: 1) mechanical properties on density and mineral content, and 2) properties on age. In accordance with Hernandez et al. ${ }^{34}$, multiple regression analysis was also performed to test the dependence of apparent modulus and strength on both BV/TV and ash fraction. Pearson correlation analysis was used to describe the association between mechanical properties. Since properties of the vertebral endplates that come from the same donor are not independent from each other, all of the above statistical analyses were performed separately for superior and inferior vertebral endplates separately. Subsequently, paired t-tests were used to identify differences in properties between superior and inferior. These comparisons were performed for endplates spanning the same intervertebral disc (i.e. L3 superior vs. L2 inferior ${ }^{29}$ and, separately, for endplates spanning the same vertebral centrum (i.e. L3 superior vs. L3 inferior) ${ }^{24,25}$ (Figure 1). For more general comparison of the difference between locations, nonparametric Wilcoxon test was used (and with no log transformation). A significance level of 5\% was used in all analyses, and any results that resulted from overly influential data points were excluded.

\section{RESULTS}


Wide variations in vertebral endplate mechanical behavior were observed among specimens. For most of the mechanical properties, values ranged more than ten-fold (Table 1). These large ranges were observed for specimens from both superior and inferior endplates, and few differences in properties between these two locations were found (Table 1). Different modes of deformation were also observed (Figure 3). Some specimens remained intact, with no visible fractures at the end of the test (Figure 3A, C), while others broke into two parts before reaching the displacement limit (Figure 3B). Different deformation scenarios were detected among the specimens in the former category: whereas some exhibited uniform curvatures across the 16mm loading span (Figure 3A) others did not (Figure 3C).

Much of the variation in apparent mechanical properties could be explained by variations in BMD and BV/TV (Table 2). Both the apparent modulus and apparent yield stress increased with increasing BMD (Figure 4A, B). The ultimate strain and fracture strain decreased with increasing BMD for inferior specimens while no dependence was seen for superior specimens (Figure 4C). Similar results were found when these four mechanical properties were regressed against BV/TV rather than BMD (Table 2). Consistent with these relationships between mechanical properties and both BMD and BV/TV, apparent modulus was positively correlated with apparent yield stress and, for inferior specimens, negatively correlated with fracture strain $(r=-0.67, p=0.02)$ (Figure 5). None of the apparent mechanical properties were correlated with ultimate strain (Table 3) or depended on age (Table 2).

In contrast to the strong dependence of the mechanical properties of the vertebral endplate on BMD and BV/TV, little dependence on measures of tissue-level density or ash density was found. None of the mechanical properties, including tissue yield stress, depended on any of the tissue-level density measurements (Table 2). Adding ash fraction to the regression of apparent 
modulus and strength against BV/TV also did not improve the fit over that obtained with BV/TV alone $(\mathrm{p}>0.091)$.

\section{DISCUSSION}

In light of the evidence that the vertebral endplate is a biomechanically critical structure, the goal of this study was to quantify its mechanical behavior. We found that BMD and BV/TV were strong predictors of many of the apparent-level mechanical properties, including modulus, yield stress, and in the case of the inferior vertebral endplate, failure strains. We also found that both the apparent modulus and apparent yield stress were inversely correlated with the failure strains. Similar values of the mechanical properties were noted between superior and inferior vertebral endplates, despite some small differences in thickness, BMD and BV/TV. In contrast to the strong dependence of apparent stiffness and strength on BMD and BV/TV, none of the mechanical properties depended on any of the tissue-level density measurements. These results indicated that amount of bone tissue present, rather than the composition of that tissue, is the most important determinant of the mechanical behavior of the vertebral endplate.

This study has several strengths. Principally, isolating the vertebral endplate from the rest of the vertebra enabled us to measure its properties directly. In prior studies, indentation tests were performed along the superior or inferior surfaces of the vertebral body, and thus those results correspond to the combined mechanical behavior of the endplate and underlying bone tissue ${ }^{17,18,20-}$ 22. Having isolated the vertebral endplate, we could also directly measure the tissue density, ash density and ash fraction, all of which can influence the mechanical behavior ${ }^{35-38}$, rather than relying on estimates of density from computed tomography scans ${ }^{24,25,27-29}$. The mechanical testing method used in this study has some additional advantages are that we used a physiological loading mode, flexion ${ }^{10}$, and a length scale on par with that of the endplate deflections and deformities 
associated with vertebral fracture and disc degeneration ${ }^{39-42}$. Finally, we tested specimens from the central endplate, rather than the ring apophysis, given the high prevalence of vertebral fractures and other types of damage that occur in this region ${ }^{9,43,44}$.

This study also has limitations. First, some subchondral trabecular bone was present in the specimens because of the irregular topography of the boundary between the vertebral endplate and trabecular centrum and because of the difficulty in discerning this boundary during specimen preparation. However, the $\mu \mathrm{CT}$ images revealed very few, if any connections between the short struts of trabeculae that were present, indicating that they would have minimal contribution to the flexural behavior. Second, the definition of the apparent yield stress using a decrease in slope in the moment-displacement curve involves some subjectivity. To mitigate bias, we also calculated the apparent yield stress using the "fully plastic bending moment" (Appendices). The two yield stresses were highly correlated with one another and exhibited very similar statistical results regarding the dependencies on density measures and correlations with apparent modulus, giving us confidence in the results we reported here. Third, the low flexural rigidity and appreciable ductility of many of the specimens meant that the displacement limit of the testing fixture was reached before these specimens reached their fracture strain or, in some cases, even ultimate strain. The limited number of data points reduced the power to detect differences in failure strains between superior and inferior endplates and to detect associations between the failure strains and other properties. A final limitation to report is the age of donors was not uniformly distributed. Only two donors of the 39 donors were under age 60. Although the predominance of older donors in our data set makes the results meaningful for aging-related conditions such as vertebral fracture, whether the results of this study extend to younger spines is unclear. 
The lack of dependence of the measured mechanical properties on ash fraction (Table 2) was somewhat unexpected. Prior work has found associations between ash fraction and several mechanical properties, particularly stiffness and strength, of cortical bone, trabecular bone, and several other mineralized tissues ${ }^{35,37,38}$. Hernandez et al. found that, for femoral cortical bone and vertebral trabecular bone, predictions of both strength and stiffness using BV/TV were improved by also using ash fraction ${ }^{34}$. However, in our study, this was generally not the case (Appendices), even though both we and Hernandez et al. found that BV/TV explained more of the variation in strength and stiffness than did the ash fraction. This discrepancy between current and previous results may be due to the larger range of BV/TV values examined by Hernandez et al. (range: 0.02 0.84 vs. $0.118 \sim 0.629$ in the current study), since they included both trabecular and cortical bone, and to differences in structure and composition between the vertebral endplate and bone in other skeletal sites. As compared to mean values reported for vertebral trabecular bone, trabecular bone in several other anatomic sites and cortical bone in the lower limb, the vertebral endplate exhibits lower tissue density and ash density, and similar ash fraction (Table 4), which altogether suggests higher water content. More detailed examination, using water, mineral, organic weight fractions, reveals a cohort of vertebral endplate specimens with high water fraction (Figure 6), but also a cohort with higher organic fraction than vertebral trabecular tissue, and overall a much larger compositional range than vertebral trabecular tissue. The vertebral endplate specimens also tended to exhibit lower mineral content than has been reported for cortical bone (Figure 6); although a comparison to the vertebral cortical shell in particular would be relevant, no such density measurements are available. These variations in aspects of composition other than ash fraction, as well as properties of the organic phase itself, such as collagen content and cross-link density ${ }^{45,46}$, may contribute more to the mechanical properties of the vertebral endplate than does ash fraction. 
The inverse trend between fracture strain and each of apparent modulus and yield stress suggests a potential compensatory mechanism in the vertebral endplate. With increased BV/TV and BMD, specimens from the inferior endplates exhibited higher stiffness and strength but lower fracture strain. This tradeoff has been found for cortical bone from different anatomic sites and species $^{38,47}$, and it indicates that specimens that are more compliant and yield at lower stresses also tend to be able to sustain greater deformation before fracturing. This tradeoff may be particularly relevant in the vertebral endplate since it is the structural boundary between the intervertebral disc and the hematopoietic tissues within the vertebral body. Fracture of this boundary has been hypothesized to trigger inflammatory cascades that can hasten degeneration of the disc ${ }^{11-13}$. Interestingly, the inverse trend between fracture strain and stiffness, strength, and density was not found for the superior vertebral endplates, even though the fracture strains of the superior vertebral endplate were as high as those in the inferior vertebral endplates.

Comparisons were made between superior and inferior endplates because of the suggestion that the former are more susceptible to failure ${ }^{30}$. Age-related vertebral fractures occur more frequently in the superior as compared to inferior half of the vertebra ${ }^{26}$, though whether this asymmetry is related to differences in the endplate properties themselves has not been established. Our finding of a lack of any differences in mechanical properties between superior and inferior endplates suggests that there may be other causes, such as the properties of the adjacent trabecular bone $^{30}$, properties of the adjacent disc, and endplate curvature. Some differences in structural properties - BV/TV, BMD and thickness - were found between superior and inferior specimens but only when the comparison was made across the disc as opposed to across the vertebral body (Table 1, Figure S2). These results suggest that the structure of the vertebral endplate may be 
intrinsic to the vertebral body rather than the motion segment or that there may be asymmetry along the superior-inferior axis in how the vertebral endplate disc interacts with the disc.

Our findings suggest new possibilities for non-invasive assessment of vertebral fracture. Non-invasive estimation of vertebral strength and stiffness from density measurements is well established $^{48,49}$, but thus far this approach has not been applied in a data-driven manner for the vertebral endplate. Prior work has shown that the density (i.e., BV/TV and BMD) of the endplate region is poorly correlated with the average density of the vertebral body, particularly in women ${ }^{27}$. Our data suggest that measurement of the density of the vertebral endplate can be useful for a more accurate estimate of its mechanical behavior and, by extension, the mechanisms of vertebral fracture. The wide variation of the properties of the vertebral endplate compared to that seen in trabecular and cortical bone at other anatomic sites further supports this approach. For example, the ranges of BV/TV, apparent modulus and apparent yield stress we have found for the vertebral endplate are larger than those for trabecular bone and cortical bone at single anatomic sites (Table $4)^{35,50}$. Using the mechanical properties obtain in the current study as input into finite element models of the vertebra may also improve the accuracy with which these models predict the where and how the vertebra deforms as it fractures ${ }^{40,51}$.

The wide variations in vertebral endplate properties are consistent with the growing understanding that this region of the spine is highly metabolically active. Bone remodeling, mineralization of the cartilage endplate, and inflammatory and repair responses triggered by damage to tissues in the endplate region may all result in changes in composition, density, microstructure and thickness of the vertebral endplate ${ }^{29,52,53}$. Bone loss due to aging and changes in the mechanical behavior of the disc due to degeneration may also affect the mechanical environment of the vertebral endplate, which in turn could result in adaptive changes in the 
properties of this structure. However, despite the complexity of how these myriad factors may affect a variety of physical properties of the vertebral endplate, the findings of this study indicate that only a subset of these, BV/TV and BMD, which largely describe the amount of bone tissue present, are strongly predictive of the mechanical behavior. Further study of how this subset of properties is affected by metabolic and mechanobiological demands, as well as genetic and other factors, will likely lead to improved predictions of the risks and consequences of spine injuries and pathologies.

\section{REFERENCES}

1. Kerttula LI, Serlo WS, Tervonen OA, Pääkkö EL, Vanharanta H V. Post-traumatic findings of the spine after earlier vertebral fracture in young patients: Clinical and MRI study. Spine (Phila Pa 1976). 2000;25(9):1104-1108. doi:10.1097/00007632-20000501000011

2. Wáng YXJ, Che-Nordin N, Deng M, et al. Osteoporotic vertebral deformity with endplate/cortex fracture is associated with higher further vertebral fracture risk: the Ms. OS (Hong Kong) study results. Osteoporos Int. 2019;30(4):897-905. doi:10.1007/s00198019-04856-4

3. Benneker LM, Heini PF, Alini M, Anderson SE, Ito K. 2004 Young investigator award winner: Vertebral endplate marrow contact channel occlusions and intervertebral disc degeneration. Spine (Phila Pa 1976). 2005;30(2):167-173.

doi:10.1097/01.brs.0000150833.93248.09

4. Melton LJ, Lane AW, Cooper C, Eastell R, O’Fallon WM, Riggs BL. Prevalence and incidence of vertebral deformities. Osteoporos Int. 1993;3(3):113-119. doi:10.1007/BF01623271 
5. O’Neill TW, Felsenbergp D, Varlow J, et al. The prevalence of vertebral deformity in european men and women: The European vertebral osteoporosis study. J Bone Miner Res. 1996;11(7):1010-1018. doi:10.1002/jbmr.5650110719

6. Hasserius R, Redlund-Johnell I, Mellström D, Johansson C, Nilsson BE, Johnell O. Vertebral deformation in urban Swedish men and women: Prevalence based on 797 subjects. Acta Orthop Scand. 2001;72(3):273-278. doi:10.1080/00016470152846619

7. Ortiz AO, Bordia R. Injury to the vertebral endplate-disk complex associated with osteoporotic vertebral compression fractures. Am J Neuroradiol. 2011;32(1):115-120. doi:10.3174/ajnr.A2223

8. Jackman TM, Hussein AI, Adams AM, Makhnejia KK, Morgan EF. Endplate deflection is a defining feature of vertebral fracture and is associated with properties of the underlying trabecular bone. J Orthop Res. 2014;32(7):880-886. doi:10.1002/jor.22620

9. Jackman TM, Hussein AI, Curtiss C, et al. Quantitative, 3D Visualization of the Initiation and Progression of Vertebral Fractures Under Compression and Anterior Flexion. J Bone Miner Res. 2016;31(4):777-788. doi:10.1002/jbmr.2749

10. Holmes AD, Hukins DW, Freemont AJ. End-plate displacement during compression of lumbar vertebra-disc-vertebra segments and the mechanism of failure. Spine (Phila Pa 1976). 1993;18(1):128-135. doi:10.1097/00007632-199301000-00019

11. Dudli S, Haschtmann D, Ferguson SJ. Fracture of the vertebral endplates, but not equienergetic impact load, promotes disc degeneration in vitro. J Orthop Res. 2012;30(5):809-816. doi:10.1002/jor.21573

12. Dudli S, Ferguson SJ, Haschtmann D. Severity and pattern of post-traumatic intervertebral disc degeneration depend on the type of injury. Spine J. 2014;14(7):1256-1264. 
doi:10.1016/j.spinee.2013.07.488

13. Wang J, Zhou Y, Zhang ZF, Li CQ, Zheng WJ, Liu J. Radiological study on disc degeneration of thoracolumbar burst fractures treated by percutaneous pedicle screw fixation. Eur Spine J. 2013;22(3):489-494. doi:10.1007/s00586-012-2462-1

14. Keaveny TM, Morgan EF, Niebur GL, Yeh OC. Biomechanics of trabecular bone. Annu Rev Biomed Eng. 2001;3.

15. Dall'Ara E, Karl C, Mazza G, et al. Tissue properties of the human vertebral body substructures evaluated by means of microindentation. J Mech Behav Biomed Mater. 2013;25:23-32. doi:10.1016/j.jmbbm.2013.04.020

16. Roy ME, Rho JY, Tsui TY, Evans ND, Pharr GM. Mechanical and morphological variation of the human lumbar vertebral cortical and trabecular bone. J Biomed Mater Res. 1999;44(2):191-197. doi:10.1002/(SICI)1097-4636(199902)44:2<191::AIDJBM9>3.0.CO;2-G

17. Grant JP, Oxland TR, Dvorak MF. Mapping the structural properties of the lumbosacral vertebral endplates. Spine (Phila Pa 1976). 2001;26(8):889-896. doi:10.1097/00007632200104150-00012

18. Grant JP, Oxland TR, Dvorak MF, Fisher CG. The effects of bone density and disc degeneration on the structural property distributions in the lower lumbar vertebral endplates. J Orthop Res. 2002;20(5):1115-1120. doi:10.1016/S0736-0266(02)00039-6

19. Hou Y, Yuan W. Influences of disc degeneration and bone mineral density on the structural properties of lumbar end plates. Spine J. 2012;12(3):249-256. doi:10.1016/j.spinee.2012.01.021

20. Ordway NR, Lu YM, Zhang X, Cheng CC, Fang H, Fayyazi AH. Correlation of cervical 
endplate strength with CT measured subchondral bone density. Eur Spine J.

2007;16(12):2104-2109. doi:10.1007/s00586-007-0482-z

21. Liu J, Hao L, Suyou L, et al. Biomechanical properties of lumbar endplates and their correlation with MRI findings of lumbar degeneration. J Biomech. 2016;49(4):586-593. doi:10.1016/j.jbiomech.2016.01.019

22. PEREY O. Fracture of the vertebral end-plate in the lumbar spine; an experimental biochemical investigation. Acta Orthop Scand Suppl. 1957;25:1-101. doi:10.3109/ort.1957.28.suppl-25.01

23. Oxland TR, Grant JP, Dvorak MF, Fisher CG. Effects of endplate removal on the structural properties of the lower lumbar vertebral bodies. Spine (Phila Pa 1976). 2003;28(8):771-777. doi:10.1097/00007632-200304150-00008

24. Hulme PA, Boyd SK, Ferguson SJ. Regional variation in vertebral bone morphology and its contribution to vertebral fracture strength. Bone. 2007;41(6):946-957. doi:10.1016/j.bone.2007.08.019

25. Zhao FD, Pollintine P, Hole BD, Adams MA, Dolan P. Vertebral fractures usually affect the cranial endplate because it is thinner and supported by less-dense trabecular bone. Bone. 2009;44(2):372-379. doi:10.1016/j.bone.2008.10.048

26. Jelsma RK, Kirsch PT, Rice JF, Jelsma LF. The radiographic description of thoracolumbar fractures. Surg Neurol. 1982;18(4):230-236. doi:10.1016/0090-3019(82)90328-7

27. McKay ML, Jackman TM, Hussein AI, Guermazi A, Liu J, Morgan EF. Association of vertebral endplate microstructure with bone strength in men and women. Bone. 2020;131(August 2019):115147. doi:10.1016/j.bone.2019.115147

28. Rodriguez AG, Rodriguez-Soto AE, Burghardt AJ, Berven S, Majumdar S, Lotz JC. 
Morphology of the human vertebral endplate. J Orthop Res. 2012;30(2):280-287. doi:10.1002/jor.21513

29. Zehra U, Robson-Brown K, Adams MA, Dolan P. Porosity and thickness of the vertebral endplate depend on local mechanical loading. Spine (Phila Pa 1976). 2015;40(15):11731180. doi:10.1097/BRS.0000000000000925

30. Wang Y, Battié MC, Boyd SK, Videman T. The osseous endplates in lumbar vertebrae: thickness, bone mineral density and their associations with age and disk degeneration. Bone. 2011;48(4):804-809. doi:10.1016/j.bone.2010.12.005

31. Doube M, Klosowski MM, Arganda-Carreras I, et al. BoneJ: Free and extensible bone image analysis in ImageJ. Bone. 2010;47(6):1076-1079. doi:10.1016/j.bone.2010.08.023

32. Morgan EF, Mason ZD, Chien KB, et al. Micro-computed tomography assessment of fracture healing: relationships among callus structure, composition, and mechanical function. Bone. 2009;44(2):335-344. doi:10.1016/j.bone.2008.10.039

33. Levenston ME, Beaupré GS, van der Meulen MCH. Improved method for analysis of whole bone torsion tests. J Bone Miner Res. 1994;9(9):1459-1465.

doi:10.1002/jbmr.5650090919

34. Hernandez CJ, Beaupré GS, Keller TS, Carter DR. The influence of bone volume fraction and ash fraction on bone strength and modulus. Bone. 2001;29(1):74-78.

doi:10.1016/S8756-3282(01)00467-7

35. Keller TS, Mao Z, Spengler DM. Young's modulus, bending strength, and tissue physical properties of human compact bone. J Orthop Res. 1990;8(4):592-603. doi:10.1002/jor.1100080416

36. Keller TS. Predicting the compressive mechanical behavior of bone. J Biomech. 
1994;27(9):1159-1168. doi:10.1016/0021-9290(94)90056-6

37. Currey JD. The mechanical consequences of variation in the mineral content of bone. $J$ Biomech. 1969;2(1):1-11. doi:10.1016/0021-9290(69)90036-0

38. Currey JD. Effects of differences in mineralization on the mechanical properties of bone. Philos Trans R Soc Lond B Biol Sci. 1984;304(1121):509-518.

doi:10.1098/rstb.1984.0042

39. Stefanakis M, Luo J, Pollintine P, Dolan P, Adams MA. ISSLS prize winner: Mechanical influences in progressive intervertebral disc degeneration. Spine (Phila Pa 1976).

2014;39(17):1365-1372. doi:10.1097/BRS.0000000000000389

40. Jackman TM, DelMonaco AM, Morgan EF. Accuracy of finite element analyses of CT scans in predictions of vertebral failure patterns under axial compression and anterior flexion. J Biomech. 2016;49(2):267-275. doi:10.1016/j.jbiomech.2015.12.004

41. Wang XR, Xu FR, Huang QL, Wáng YXJ. Radiological features of traumatic vertebral endplate fracture: an analysis of 194 cases with 263 vertebral fractures. Chin Med J (Engl). 2020;133(22):2696-2702. doi:10.1097/CM9.0000000000000919

42. Choi W, Song S, Chae S, Ko S. Comparison of the extent of degeneration among the normal disc, immobilized disc, and immobilized disc with an endplate fracture. CiOS Clin Orthop Surg. 2017;9(2):193-199. doi:10.4055/cios.2017.9.2.193

43. Berg-Johansen B, Fields AJ, Liebenberg EC, Li A, Lotz JC. Structure-function relationships at the human spinal disc-vertebra interface. J Orthop Res. 2018;36(1):192201. doi:10.1002/jor.23627

44. Chen L, Battié MC, Yuan Y, Yang G, Chen Z, Wang Y. Lumbar vertebral endplate defects on magnetic resonance images: prevalence, distribution patterns, and associations 
with back pain. Spine J. 2020;20(3):352-360. doi:10.1016/j.spinee.2019.10.015

45. Zhang Y, McNerny EG, Terajima M, et al. Loss of BMP signaling through BMPR1A in osteoblasts leads to greater collagen cross-link maturation and material-level mechanical properties in mouse femoral trabecular compartments. Bone. 2016;88:74-84.

doi:10.1016/j.bone.2016.04.022

46. Banse X, Sims TJ, Bailey AJ. Mechanical properties of adult vertebral cancellous bone: Correlation with collagen intermolecular cross-links. J Bone Miner Res. 2002;17(9):16211628. doi:10.1359/jbmr.2002.17.9.1621

47. Currey JD. The design of mineralised hard tissues for their mechanical functions. J Exp Biol. 1999;202(23):3285-3294.

48. Kanis JA, Johnell O. Requirements for DXA for the management of osteoporosis in Europe. Osteoporos Int. 2005;16(3):229-238. doi:10.1007/s00198-004-1811-2

49. Kopperdahl DL, Morgan EF, Keaveny TM. Quantitative computed tomography estimates of the mechanical properties of human vertebral trabecular bone. J Orthop Res. 2002;20(4):801-805. doi:10.1016/S0736-0266(01)00185-1

50. Morgan EF, Keaveny TM. Dependence of yield strain of human trabecular bone on anatomic site. J Biomech. 2001;34(5):569-577. doi:10.1016/S0021-9290(01)00011-2

51. Pahr DH, Zysset PK. A comparison of enhanced continuum FE with micro FE models of human vertebral bodies. J Biomech. 2009;42(4):455-462.

doi:10.1016/j.jbiomech.2008.11.028

52. Bernick S, Cailliet R. Vertebral end-plate changes with aging of human vertebrae.pdf. Spine (Phila Pa 1976). 1982;7(2):97-102. doi:10.1097/00007632-198203000-00002

53. Luoma K, Vehmas T, Kerttula L, Grönblad M, Rinne E. Chronic low back pain in relation 
to Modic changes, bony endplate lesions, and disc degeneration in a prospective MRI study. Eur Spine J. 2016;25(9):2873-2881. doi:10.1007/s00586-016-4715-x

54. Snyder BD, Piazza S, Edwards WT, Hayes WC. Role of trabecular morphology in the etiology of age-related vertebral fractures. Calcif Tissue Int. 1993;53(1 Supplement):1422. doi:10.1007/BF01673396

55. Morgan EF, Bayraktar HH, Keaveny TM. Trabecular bone modulus-density relationships depend on anatomic site. J Biomech. 2003;36(7):897-904. doi:10.1016/S00219290(03)00071-X

56. Galante J, Rostoker W, Ray RD. Physical properties of trabecular bone. Calcif Tissue Res. 1970;5(3):236-246. doi:10.1007/BF02017552

57. Schileo E, Dall'Ara E, Taddei F, et al. An accurate estimation of bone density improves the accuracy of subject-specific finite element models. J Biomech. 2008;41(11):24832491. doi:10.1016/j.jbiomech.2008.05.017

58. Yeni YN, Brown CU, Norman TL. Influence of bone composition and apparent density on fracture toughness of the human femur and tibia. Bone. 1998;22(1):79-84. doi:10.1016/S8756-3282(97)00227-5

59. Snyder SM, Schneider E. Estimation of mechanical properties of cortical bone by computed tomography. J Orthop Res. 1991;9(3):422-431. doi:10.1002/jor.1100090315

60. Cendre E, Mitton D, Roux JP, et al. High-resolution computed tomography for architectural characterization of human lumbar cancellous bone: Relationships with histomorphometry and biomechanics. Osteoporos Int. 1999;10(5):353-360. doi:10.1007/s001980050240

61. Ohlsson C, Sundh D, Wallerek A, et al. Cortical bone area predicts incident fractures 
independently of areal bone mineral density in older men. J Clin Endocrinol Metab. 2017;102(2):516-524. doi:10.1210/jc.2016-3177

62. Boughton OR, Ma S, Cai X, et al. Computed tomography porosity and spherical indentation for determining cortical bone millimetre-scale mechanical properties. Sci Rep. 2019;9(1):1-15. doi:10.1038/s41598-019-43686-6

63. Chen H, Zhou X, Shoumura S, Emura S, Bunai Y. Age- And gender-dependent changes in three-dimensional microstructure of cortical and trabecular bone at the human femoral neck. Osteoporos Int. 2010;21(4):627-636. doi:10.1007/s00198-009-0993-z

64. Iori G, Heyer F, Kilappa V, et al. BMD-based assessment of local porosity in human femoral cortical bone. Bone. 2018;114(December 2017):50-61. doi:10.1016/j.bone.2018.05.028

65. Tassani S, Öhman C, Baruffaldi F, Baleani M, Viceconti M. Volume to density relation in adult human bone tissue. J Biomech. 2011;44(1):103-108.

doi:10.1016/j.jbiomech.2010.08.032

66. Kaneko TS, Pejcic MR, Tehranzadeh J, Keyak JH. Relationships between material properties and CT scan data of cortical bone with and without metastatic lesions. Med Eng Phys. 2003;25(6):445-454. doi:10.1016/S1350-4533(03)00030-4

67. Öhman C, Baleani M, Pani C, et al. Compressive behaviour of child and adult cortical bone. Bone. 2011;49(4):769-776. doi:10.1016/j.bone.2011.06.035

69. Gere J and Goodno B. Mechanics of Materials. Seventh Edition: 504-510 


\section{APPENDICES}

Because of the subjectivity in determine the end of elastic regime from moment-displacement curve, a second measure of the apparent yield stress $\sigma_{\mathrm{u}}$ was calculated. The tissue of the vertebral endplate was assumed to be perfectly plastic following yield, and the maximum moment was assumed to correspond to the 'fully-plastic bending moment' ${ }^{69} . \sigma_{\mathrm{u}}$ was calculated as:

$$
\sigma_{\mathrm{u}}=\frac{4 \times \mathrm{M}_{\mathrm{u}}}{\mathrm{b} \times \mathrm{h}^{2}}
$$

where $b$ and $h$ are the width and thickness of the central $16 \mathrm{~mm}$ of the specimen.

The mean \pm STD of $\sigma_{\mathrm{u}}$ for superior and inferior vertebral endplates were $4.00 \pm 2.80$ (range: $1.28 \sim 11.2 \mathrm{MPa})$ and $5.35 \pm 3.83 \mathrm{MPa}(0.84 \sim 14.2 \mathrm{MPa})$ respectively. $\sigma_{\mathrm{u}}$ was highly correlated with $\sigma_{\mathrm{y}}(\mathrm{r}>0.950, \mathrm{p}<0.05)$ and, like $\sigma_{\mathrm{y}}, \sigma_{\mathrm{u}}$ increased with increasing BV/TV and BMD for both superior and inferior specimens $\left(\mathrm{R}^{2}>0.43, \mathrm{p}<0.05\right)$. Adding ash fraction to the regression of $\sigma_{\mathrm{u}}$ against $\mathrm{BV} / \mathrm{TV}$ was improved for inferior vertebral endplates only $\left(\mathrm{R}^{2}\right.$ increased from 0.495 to $0.633(\mathrm{p}=0.015$, Figure $\mathrm{S} 1)$. 

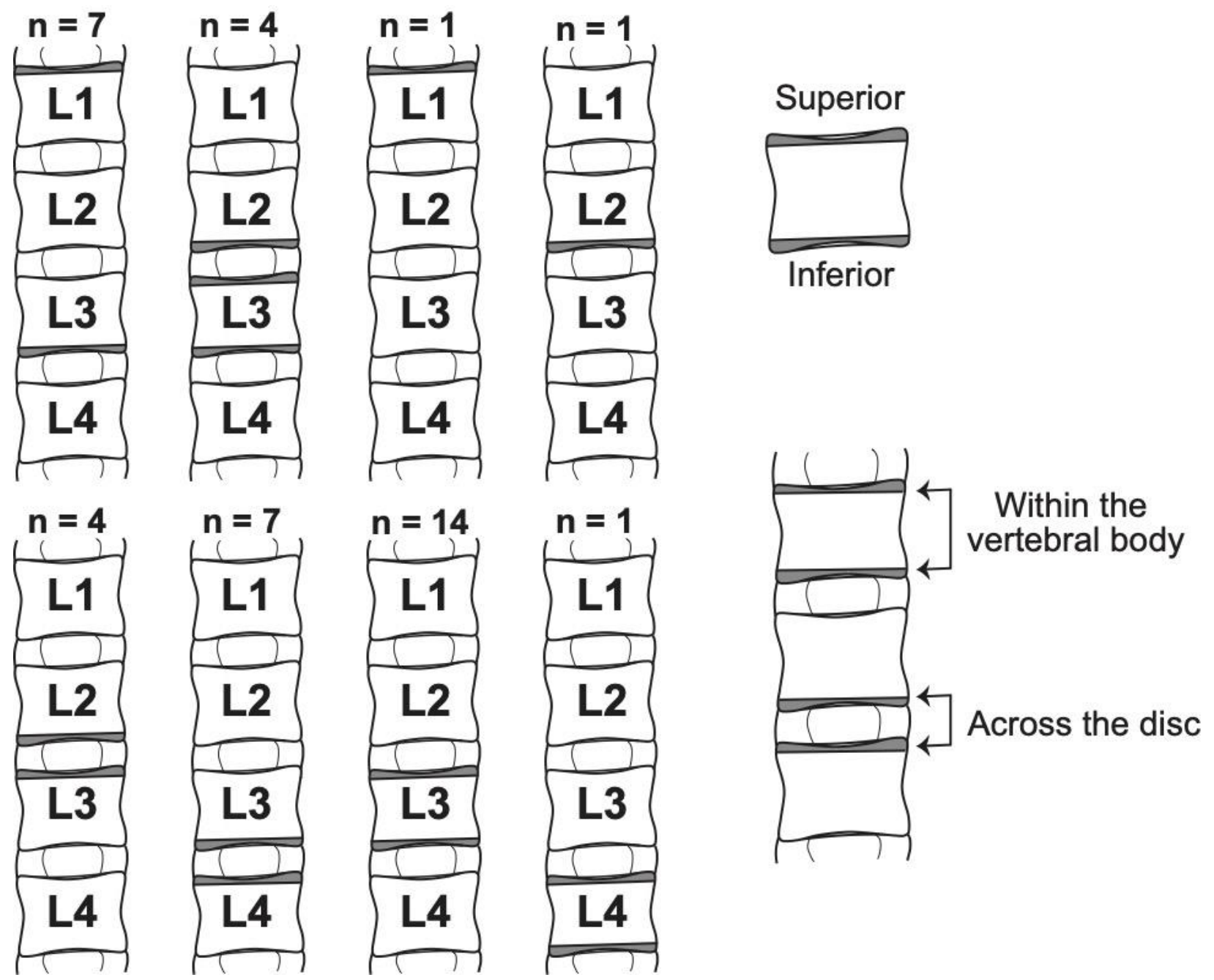

FIGURE 1 Origin of the vertebral endplate specimens used in this study with respect to the 39

L1-L4 spine segments. Gray shading indicates where the specimens were harvested from. $\mathrm{n}$ is the number of spine segments in each dissection scenario. Superior and inferior endplates collected from the same spine can be paired within the same vertebral body or across the same disc 


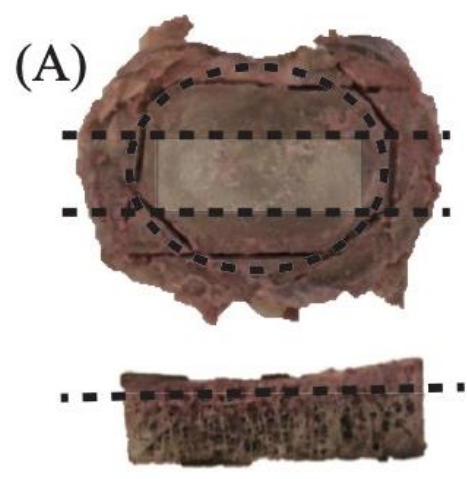

(B)
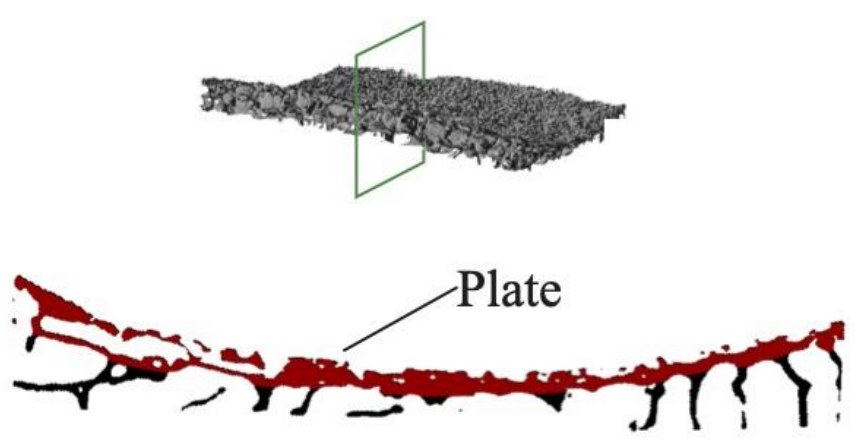

(C)

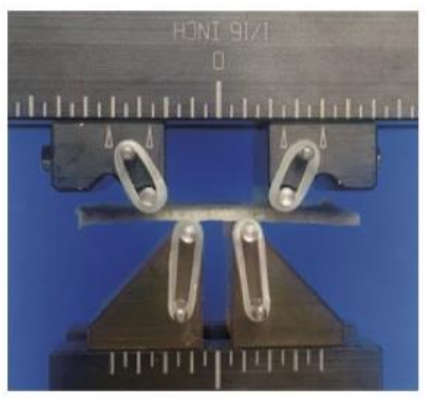

(D)

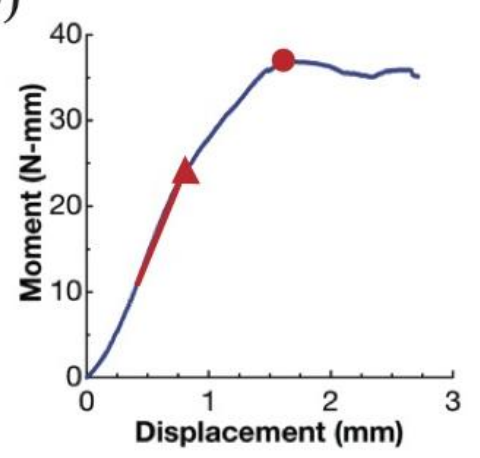

FIGURE 2 A, Specimen preparation (dotted lines represent cuts): The ring apophysis of the superior or inferior half of the vertebra was first trimmed off using bone saw followed by a transverse cut to reduce the thickness to $5 \mathrm{~mm}$. Then two sagittal cuts were made to dissect the central $13 \mathrm{~mm}$ region. The last cut further reduced the thickness to $1.5 \mathrm{~mm}$. B, A $\mu \mathrm{CT}$ crosssection of the vertebral endplate. The plate itself is false-colored red. C, Four-point-bend test setup. The bottom two pins are loading pins with inner span of $8 \mathrm{~mm}$. The top two pins are supporting pins with outer span of $16 \mathrm{~mm}$. D, Representative moment-displacement curve. The red line, red triangle and red dot mark the slope used to compute the elastic modulus, yield point and ultimate point respectively 


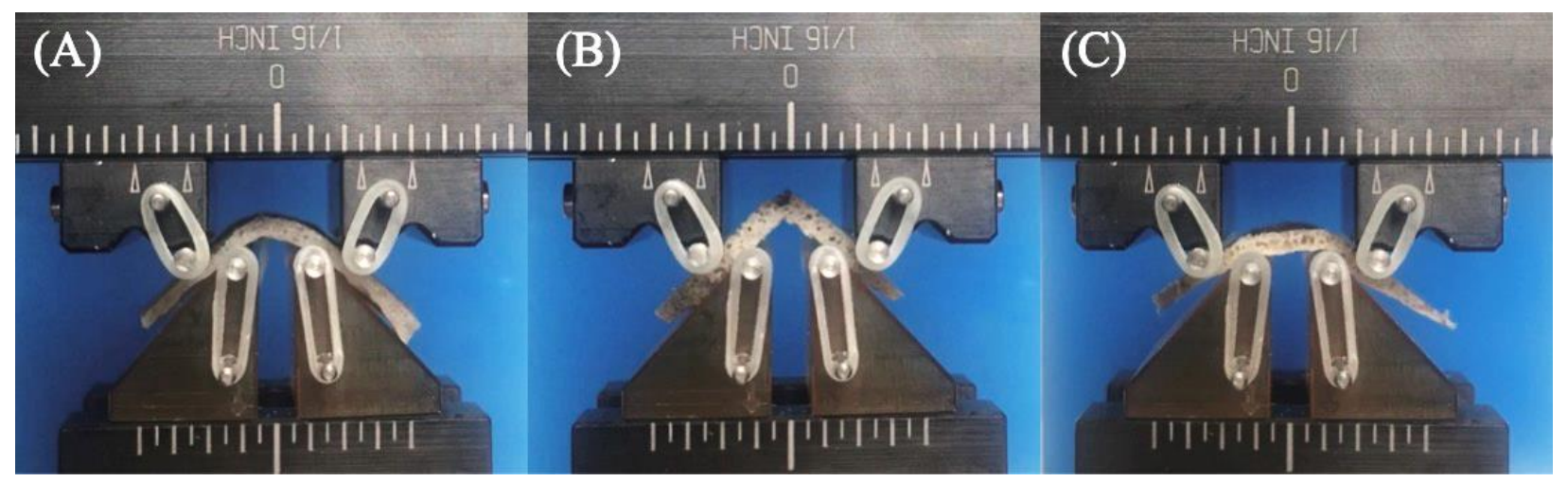

FIGURE 3 Vertebral endplates exhibited different modes of deformation and failure: A, Uniform curvature across the bending span; B, Breakage; and C, Non-uniform curvature across the bending span. All images correspond to the end of the test. The image in A illustrates the displacement limit of the test, as further applied displacement would result in pinching of the specimen between the upper pins and bottom fixture. 
TABLE 1 Properties of superior and inferior vertebral endplate specimens tested in this study.

Data are presented as mean \pm S.D (minimum, maximum)

\begin{tabular}{|c|c|c|}
\hline & \multicolumn{2}{|c|}{ Location } \\
\hline & Superior & Inferior \\
\hline Plate Thickness (mm) & $0.225 \pm 0.073(0.138,0.457)$ & $0.265 \pm 0.092(0.134,0.509)$ \\
\hline$\rho_{\text {tissue }}\left(\mathrm{g} / \mathrm{cm}^{3}\right)$ & $1.519 \pm 0.107(1.291,1.753)$ & $1.498 \pm 0.107(1.265,1.696)$ \\
\hline BV/TV $(-)^{a, c}$ & $0.246 \pm 0.07(0.133,0.432)$ & $0.296 \pm 0.109(0.118,0.629)$ \\
\hline 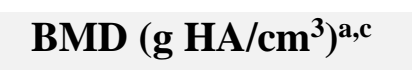 & $0.286 \pm 0.074(0.168,0.484)$ & $0.337 \pm 0.114(0.132,0.641)$ \\
\hline TMD (g HA/cm $\left.{ }^{3}\right)$ & $0.998 \pm 0.029(0.925,1.072)$ & $1.002 \pm 0.028(0.937,1.058)$ \\
\hline$p(-)$ & $0.595 \pm 0.084(0.364,0.779)$ & $0.607 \pm 0.097(0.369,0.847)$ \\
\hline$\rho_{\text {ash }}\left(\mathrm{g} / \mathrm{cm}^{3}\right)$ & $0.780 \pm 0.174(0.413,1.156)$ & $0.823 \pm 0.171(0.525,1.354)$ \\
\hline E (MPa) & $178 \pm 158(46.0,713)$ & $208 \pm 177(15.5,879)$ \\
\hline$\sigma_{y}(\mathbf{M P a})$ & $3.48 \pm 2.51(0.94,11.8)$ & $4.40 \pm 3.45(0.60,14.3)$ \\
\hline$\varepsilon_{\mathrm{u}}(-)$ & $0.065 \pm 0.028(0.016,0.134)$ & $0.061 \pm 0.027(0.013,0.116)$ \\
\hline $\mathcal{E}_{\mathrm{f}}(-)$ & $0.079 \pm 0.033(0.020,0.133)$ & $0.080 \pm 0.019(0.055,0.121)$ \\
\hline$\sigma_{\text {tissue }}(\mathbf{M P a})^{\mathbf{b}}$ & $27.49 \pm 11.60(10.05,56.42)$ & $38.26 \pm 19.28(6.359,75.47)$ \\
\hline Organic\% & $36.1 \% \pm 8.5 \%(19.2 \%, 57.3 \%)$ & $35.3 \% \pm 9.7 \%(14.3 \%, 61.5 \%)$ \\
\hline Mineral\% & $52.7 \% \pm 8.1 \%(31.8 \%, 67.9 \%)$ & $54.2 \% \pm 8.8 \%(36.0 \%, 79.2 \%)$ \\
\hline Water\% & $11.2 \% \pm 7.6 \%(0.9 \%, 36.2 \%)$ & $10.6 \% \pm 6.2 \%(2.2 \%, 29.7 \%)$ \\
\hline
\end{tabular}

${ }^{\mathrm{a}} \mathrm{p}<0.05$ for superior vs. inferior vertebral endplates, according to an unpaired comparison

(Wilcoxon test)

${ }^{b} \mathrm{p}<0.05$ for superior vs. inferior endplates when compared within the same vertebral body

${ }^{c} \mathrm{p}<0.05$ for superior vs. inferior endplates when compared across the disc 
TABLE 2 Coefficient of determination $\left(R^{2}\right)$ for univariate linear regressions of mechanical properties against age and measures of structure and composition. Regressions were performed through a general linear model using log transformations of the data. S and I represent the superior and inferior vertebral endplate, respectively

\begin{tabular}{|c|c|c|c|c|c|c|}
\hline \multirow{3}{*}{ Age } & Age & $E(\mathbf{M P a})$ & $\sigma_{y}(\mathrm{MPa})$ & $\varepsilon_{\mathrm{u}}(-)$ & $\varepsilon_{\mathrm{f}}(-)$ & $\sigma_{\text {tissue }}(\mathrm{MPa})$ \\
\hline & & S:0.019 & S: 0.031 & S: $0.243^{*}$ & S: 0.027 & S: 0.042 \\
\hline & & I: 0.012 & I: 0.029 & I: 0.060 & I: 0.023 & I: 0.022 \\
\hline \multirow{2}{*}{$\rho_{\text {tissue }}\left(\mathrm{g} / \mathrm{cm}^{3}\right)$} & S: 0.081 & S: 0.001 & S: 0.001 & S: 0.003 & S: 0.058 & S: 0.117 \\
\hline & I: 0.048 & I: 0.005 & I: 0.002 & I: 0.098 & I: 0.110 & I: 0.008 \\
\hline \multirow{2}{*}{ BV/TV (-) } & S: 0.019 & S: $0.501^{*}$ & S: $0.406^{*}$ & S: 0.089 & S: 0.284 & - \\
\hline & I: 0.043 & $\mathrm{I}: 0.530^{*}$ & $\mathrm{I}: 0.512^{*}$ & I: $0.292^{*}$ & I: $0.454^{*}$ & \\
\hline \multirow{2}{*}{ BMD (g HA/cm $\left.{ }^{3}\right)$} & S: 0.023 & S: $0.517^{*}$ & S: $0.495^{*}$ & S: 0.126 & S: 0.278 & - \\
\hline & I: 0.030 & $\mathrm{I}: 0.512^{*}$ & I: $0.429^{*}$ & I: $0.314^{*}$ & I: $0.465^{*}$ & \\
\hline \multirow{2}{*}{ TMD (g HA/cm $\left.{ }^{3}\right)$} & S: 0.017 & S: 0.043 & S: 0.011 & S: 0.021 & S: 0.009 & S: 0.027 \\
\hline & I: $0.268^{*}$ & I: 0.001 & I: 0.001 & I: 0.043 & I: 0.050 & I: 0.013 \\
\hline \multirow{2}{*}{$p(-)$} & S: 0.010 & S: 0.017 & S: 0.005 & S: 0.013 & S: 0.070 & S: 0.001 \\
\hline & I: 0.022 & I: 0.005 & I: 0.002 & I: 0.021 & I: 0.137 & I: 0.001 \\
\hline \multirow{2}{*}{$\rho_{\text {ash }}\left(\mathrm{g} / \mathrm{cm}^{3}\right)$} & S: 0.022 & S: 0.018 & S: 0.014 & S: 0.016 & S: 0.034 & S: 0.013 \\
\hline & I: 0.018 & I: 0.011 & I: 0.008 & I: 0.010 & I: 0.072 & I: 0.002 \\
\hline
\end{tabular}

TABLE 3 Pearson correlation (r) mechanical properties. S and I represent the superior and inferior vertebral endplate respectively

\begin{tabular}{cccc}
\hline & E (MPa) & $\sigma_{\mathbf{y}}(\mathbf{M P a})$ & $\varepsilon_{\mathrm{u}}(-)$ \\
$\sigma_{\mathbf{y}}(\mathbf{M P a})$ & S: $0.934^{*}$ & - & - \\
& I: $0.965^{*}$ & & \\
$\varepsilon_{\mathrm{u}}(-)$ & S: -0.301 & S: -0.282 & - \\
& I: -0.382 & I: -0.305 & \\
$\varepsilon_{\mathrm{f}}(-)$ & S: -0.450 & S: -0.278 & S: $0.798^{*}$ \\
& I: $-0.671^{*}$ & I: $-0.719^{*}$ & I: $0.900^{*}$ \\
\hline$* \mathrm{p}<0.05$ & & &
\end{tabular}



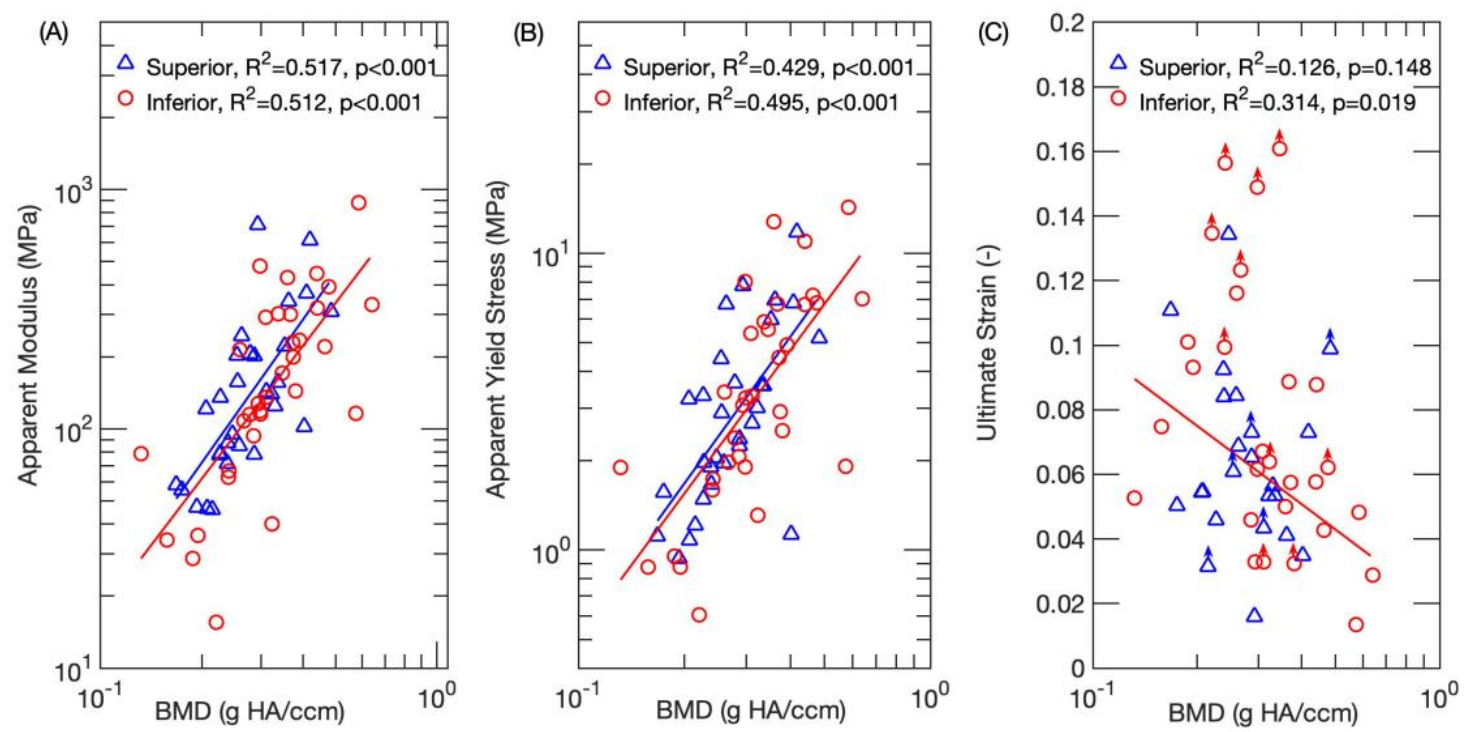

FIGURE 4 Log-log plots for A, apparent modulus; and B, apparent yield stress as a function of BMD. Regression lines are shown where applicable. Both the apparent modulus and yield stress increased with increasing BMD, for both superior and inferior endplates. C, Semi-log plot for ultimate strain as a function of BMD. An inverse relationship was found for the inferior vertebral endplates only. Points labeled with an arrow correspond to specimens that did not reach their ultimate point before the end of the test. The points are position at the largest strain that was measured in the test. These points were not included in the statistical analyses 

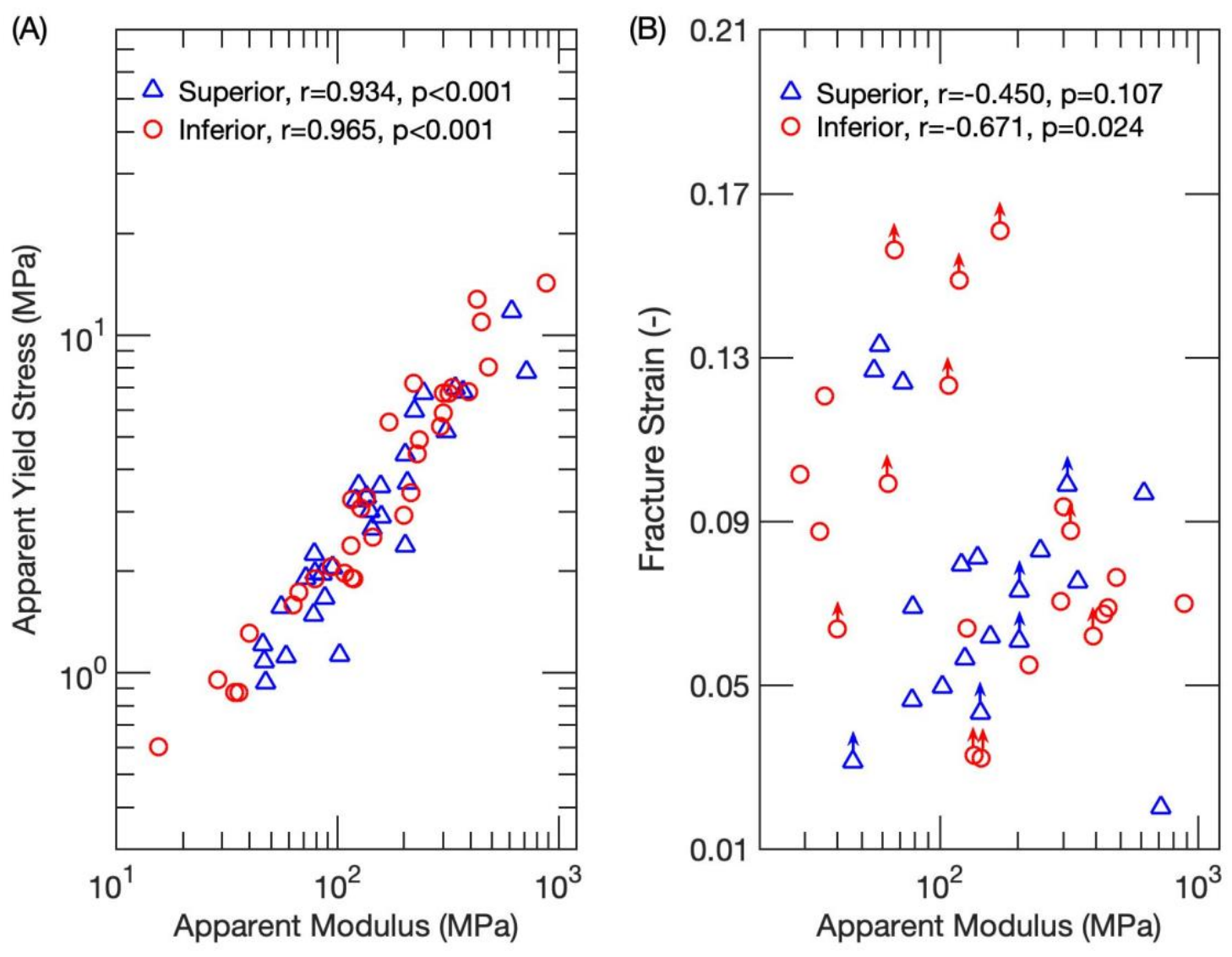

FIGURE 5 A, Log-log plots for apparent yield stress against apparent modulus for superior and inferior vertebral endplates. A positive correlation was found for both superior $(r=0.934)$ and inferior $(r=0.965)$ specimens. B, Semi-log plot for fracture strain against apparent modulus. Only fracture strain of inferior vertebral endplate was negatively correlated with apparent modulus. Points labeled with an arrow correspond to specimens that did not reach their fracture point before the end of the test. The points are position at the largest strain that was measured in the test. These points were not included in the statistical analyses 
TABLE 4 Measures of density and ash fraction for the human vertebral endplate, human trabecular bone, and human cortical bone

\begin{tabular}{|c|c|c|c|c|}
\hline Properties & Bone Type & Anatomic Site & Mean \pm STD & Range \\
\hline \multirow{11}{*}{ 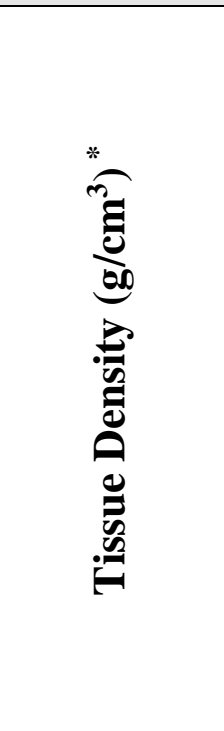 } & $\begin{array}{l}\text { Vertebral } \\
\text { Endplate }\end{array}$ & Vertebral Body & $1.508 \pm 0.107$ & $1.265,1.753$ \\
\hline & \multirow{3}{*}{$\begin{array}{l}\text { Trabecular } \\
\text { Bone }\end{array}$} & Vertebral Body ${ }^{54}$ & $1.93 \pm 0.068$ & NR \\
\hline & & Vertebral Body ${ }^{55}$ & $2.01 \pm 0.17$ & $1.76,2.41$ \\
\hline & & Proximal Tibia $^{55}$ & $2.08 \pm 0.05$ & $1.88,2.13$ \\
\hline & \multirow{7}{*}{$\begin{array}{l}\text { Cortical } \\
\text { Bone }\end{array}$} & Vertebral Body ${ }^{56}$ & $1.79 \pm 0.04$ & $1.42,1.94$ \\
\hline & & Femoral Neck ${ }^{55}$ & $2.11 \pm 0.07$ & $1.93,2.20$ \\
\hline & & Femoral Diaphysis ${ }^{57}$ & $1.84 \pm 0.13$ & $1.51,2.00$ \\
\hline & & Femoral Diaphysis ${ }^{58}$ & $1.88 \pm 0.05$ & NR \\
\hline & & Greater Trochanter ${ }^{55}$ & $2.09 \pm 0.03$ & $2.02,2.15$ \\
\hline & & Tibial Diaphysis ${ }^{58}$ & $1.80 \pm 0.19$ & NR \\
\hline & & Tibial Diaphysis ${ }^{59}$ & $1.86 \pm 0.06$ & $1.75,1.95$ \\
\hline \multirow{14}{*}{$\begin{array}{l}\underset{E}{E} \\
\underset{\infty}{E}\end{array}$} & \multirow{2}{*}{$\begin{array}{l}\text { Vertebral } \\
\text { Endplate }\end{array}$} & Vertebral Body & $0.272 \pm 0.096$ & $0.118,0.629$ \\
\hline & & Vertebral Body ${ }^{29}$ & $0.36 \pm 0.13$ & $0.10,0.68$ \\
\hline & \multirow{7}{*}{$\begin{array}{l}\text { Trabecular } \\
\text { Bone }\end{array}$} & Vertebral Body ${ }^{56}$ & $0.13 \pm 0.01$ & $0.05,0.27$ \\
\hline & & Vertebral Body ${ }^{60}$ & $0.18 \pm 0.06$ & $0.05,0.27$ \\
\hline & & Vertebral Body ${ }^{55}$ & $0.09 \pm 0.02$ & $0.04,0.18$ \\
\hline & & Proximal Tibia ${ }^{55}$ & $0.11 \pm 0.04$ & $0.05,0.20$ \\
\hline & & Femoral Neck ${ }^{55}$ & $0.27 \pm 0.07$ & $0.12,0.36$ \\
\hline & & Greater Trochanter 55 & $0.11 \pm 0.02$ & $0.07,0.14$ \\
\hline & & Distal Tibia ${ }^{61}$ & $0.15 \pm 0.03$ & NR \\
\hline & \multirow{5}{*}{$\begin{array}{l}\text { Cortical } \\
\text { bone }\end{array}$} & Distal Tibia $^{61}$ & $0.88 \pm 0.04$ & NR \\
\hline & & Femoral Neck ${ }^{62}$ & $0.89 \pm 0.09$ & $0.6,0.98$ \\
\hline & & Femoral Neck ${ }^{63}$ & $0.92 \pm 0.03$ & $0.84,0.96$ \\
\hline & & Femoral Diaphysis ${ }^{64}$ & $0.83 \pm 0.11$ & $0.24,0.98$ \\
\hline & & $\begin{array}{l}\text { Diaphysis from both } \\
\text { Tibia and femur }\end{array}$ & $0.83 \pm 0.13$ & $0.54,0.97$ \\
\hline
\end{tabular}




\begin{tabular}{|c|c|c|c|c|}
\hline Properties & Bone & Anatomic Site & Mean \pm STD & Range \\
\hline \multirow{8}{*}{ 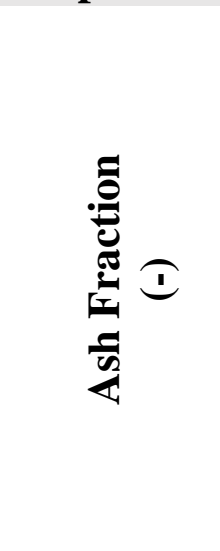 } & $\begin{array}{l}\text { Vertebral } \\
\text { Endplate }\end{array}$ & Vertebral Body & $0.601 \pm 0.090$ & $0.364,0.847$ \\
\hline & \multirow{2}{*}{$\begin{array}{l}\text { Trabecular } \\
\text { Bone }\end{array}$} & Vertebral Body ${ }^{56}$ & $0.64 \pm 0.02$ & $0.59,0.69$ \\
\hline & & Vertebral Body ${ }^{36}$ & $0.61 \pm 0.02$ & $0.53,0.66$ \\
\hline & \multirow{5}{*}{$\begin{array}{l}\text { Cortical } \\
\text { Bone }\end{array}$} & Femoral Diaphysis ${ }^{36}$ & $0.58 \pm 0.10$ & $0.17,0.66$ \\
\hline & & Femoral Diaphysis ${ }^{35}$ & $0.65 \pm 0.02$ & NR \\
\hline & & Femoral Diaphysis ${ }^{58}$ & $0.64 \pm 0.01$ & NR \\
\hline & & Tibial Diaphysis $^{58}$ & $0.63 \pm 0.02$ & NR \\
\hline & & Tibial Diaphysis $^{59}$ & $0.66 \pm 0.02$ & $0.61,0.69$ \\
\hline \multirow{7}{*}{ 昜 } & $\begin{array}{l}\text { Vertebral } \\
\text { Endplate }\end{array}$ & Vertebral Body & $0.802 \pm 0.173$ & $0.413,1.354$ \\
\hline & $\begin{array}{c}\text { Trabecular } \\
\text { Bone }\end{array}$ & Vertebral Body ${ }^{56}$ & $1.01 \pm 0.03$ & $0.78,1.17$ \\
\hline & \multirow{5}{*}{$\begin{array}{l}\text { Cortical } \\
\text { Bone }\end{array}$} & Femoral Diaphysis ${ }^{57}$ & $1.10 \pm 0.08$ & $0.9,1.21$ \\
\hline & & Femoral Diaphysis ${ }^{66}$ & $1.05 \pm 0.14$ & $0.64,1.20$ \\
\hline & & $\begin{array}{l}\text { Diaphysis from both Tibia } \\
\text { and femur }\end{array}$ & $0.99 \pm 0.13$ & $0.68,1.22$ \\
\hline & & Children Femoral shaft ${ }^{67}$ & $0.92 \pm 0.15$ & $0.58,1.17$ \\
\hline & & $\begin{array}{l}\text { Adult femoral and tibial } \\
\text { shaft }^{67}\end{array}$ & $1.15 \pm 0.07$ & $1.00,1.29$ \\
\hline
\end{tabular}

*For cortical bone, the specimen volume used to calculate tissue density and ash density included pore space corresponding to vascular porosity as well as lacunar-canalicular porosity NR: not reported by the study 


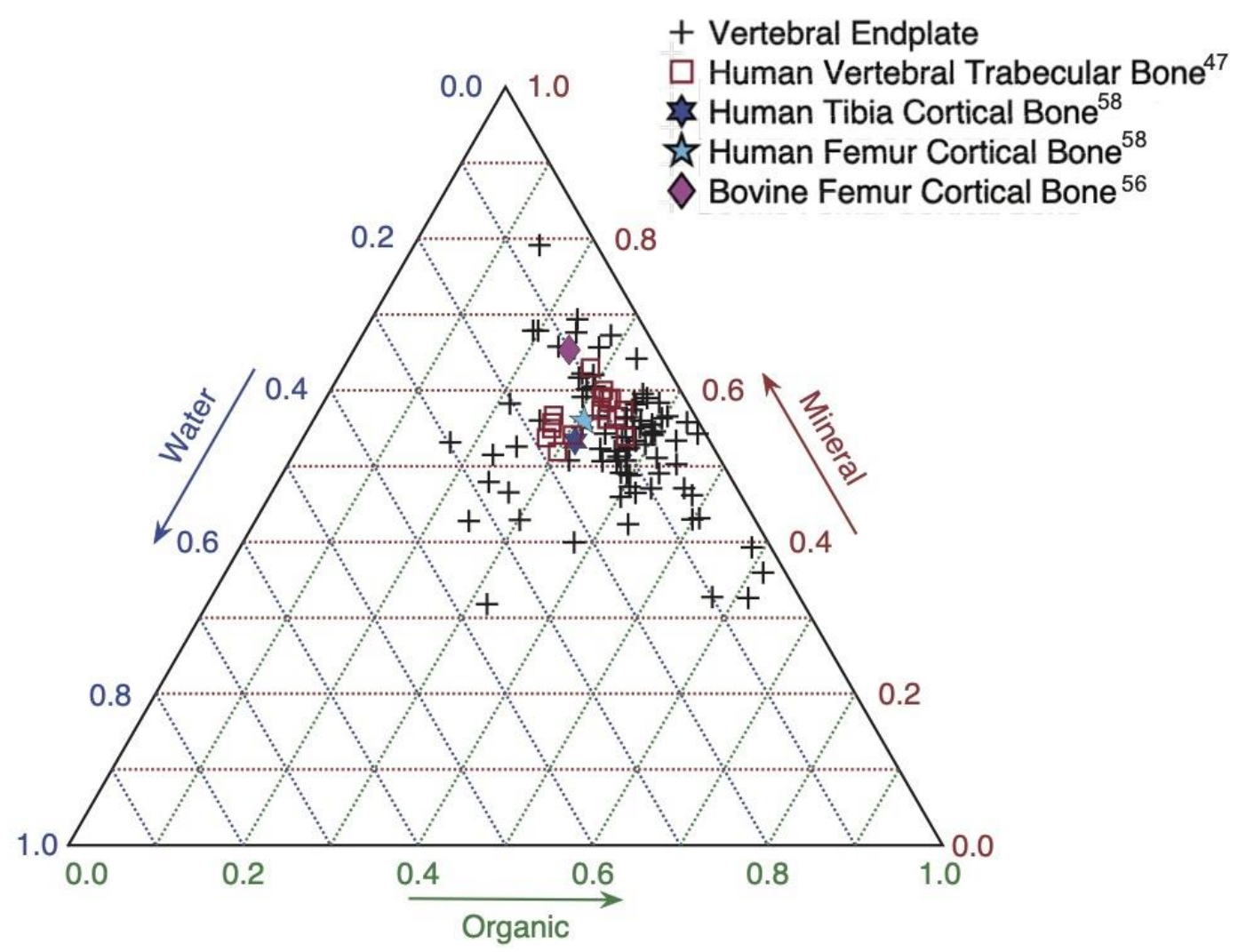

FIGURE 6 Ternary plot of the mineral, organic and water weight fractions 